\title{
Clinicodemographic profile of head neck oncology patients in COVID-19 pandemic: A descriptive study in a tertiary hospital of Eastern Nepal
}

\author{
Rishikesh Thakur ${ }^{1}$, Sanjeev Kumar Thakur ${ }^{2}$ \\ ${ }^{1}$ Lecturer, ${ }^{2}$ Associate Professor, Department of Otorhinolaryngology and Head Neck Surgery, Nobel Medical College \\ and Teaching Hospital, Biratnagar
}

Background: Head neck cancer needs early diagnosis and treatment for better outcome. There is lack of oncological awareness in our scenario and which is further masked by COVID-19 pandemic. Further masked by scarce published data from eastern Nepal. Aims and Objective: Our study aims to fulfil the lacunae and helps in providing head neck oncological clinicodemographic profile that will be useful for oncological awareness and early detection that ultimately will lead proper management leading to good outcome. Materials and Methods: A descriptive cross sectional study performed during the COVID-19 pandemic between $15^{\text {th }}$ March 2020 to $12^{\text {th }}$ February 2021 for the biopsy or cytology proven head neck cancer patients. Demographic profile and clinical parameters were recorded. Statistical analysis was performed using SPSS16 software. Analysis of clinical parameters with subsites was done by Pearson Chi Square test. The $\mathrm{p}$ value $<0.05$ was considered significant. Results: Fifty-six head neck cancer patients were enrolled as per inclusion criteria. Median age and median duration of clinical presentation were 59.5 years and 3.5 months respectively. Higher prevalence of disease noticed in male and higher age group ( $>60$ years). Thyroid cancer was most common site $(19.1 \%)$ followed by oral cancer (14.3\%). Most common presentation was swelling (55.4\%) followed by non-healing ulcer (14.3\%). Male patients and having history of tobacco/alcohol use had more site specific cancer as evaluated by Pearson chi square test by SPSS-16 with $\mathrm{p}$-value of 0.021 and 0.004 respectively. Conclusions: Most common subsite is thyroid followed by oral cavity. Swelling is most common clinical presentation. Advancing age, male sex and history of tobacco/alcohol use were risk factors.

Key words: Head Neck; Oral cancer; Thyroid cancer

\section{INTRODUCTION}

Head neck cancer represents one of major burden globally and more in Asian territory. ${ }^{1}$ According to National cancer registry 2018 of Nepal, it is the $3^{\text {rd }}$ most common cancer overall ( $\geq 12.2 \%$ of all cancers) and $2^{\text {nd }}$ most common in male ( $\geq 18 \%$ of all cancers). ${ }^{2}$ Proper clinical, histopathological and radiological evaluation are done to diagnosis and stage the disease. Early stage (stage I, II) usually requires single modality of treatment while advanced stage (III, IV) require multimodality. ${ }^{3}$
Surgical treatments \pm adjuvant (radiation or chemo radiation) is preferred curative modality in head neck cancer. $^{4}$

The ongoing pandemic of COVID -19 has affected the patient care in all aspect and so for head neck. There is lack of oncological awareness in our scenario and which is further masked by COVID-19 pandemic by decreased availability for trained health care worked for oncology leading to advanced stage of presentation to tertiary care hospital and thus to poor outcome. 
There are many published data across the globe but that doesn't reflect the actual representation for our country especially eastern region because of geographical variation and social acceptance for use of tobacco and alcohol related substances. Further there is scarce of published data not only from eastern part of Nepal. Our study aims to fulfil the lacunae and helps in providing head neck oncological clinicodemographic profile that will be useful for oncological awareness and early detection that ultimately will lead proper management leading to good outcome.

\section{MATERIALS AND METHODS}

A descriptive cross sectional study done in department of Otorhinolaryngology and head neck surgery during the COVID-19 pandemic between $15^{\text {th }}$ March 2020 to $12^{\text {th }} \mathrm{Feb}$ 2021. It included the biopsy or cytology proven head neck cancer patients. Informed and written consent was obtained from the subjects and ethical clearance was obtained from institute ethical committee (Ref no - 368/2020). Patients demographic profile and clinical parameters were recorded. Statistical analysis was performed using SPSS-16 software. Analysis of clinical parameters with subsites was done by Pearson Chi Square test. The $\mathrm{p}$ value $<0.05$ was considered significant.

\section{RESULTS}

Approximately 1200 patients visited the otorhinolaryngology outpatient during the study period. Out of which 56 patients were enrolled for our study as per inclusion criteria.

The age and sex wise distribution of our patient cohort is shown in Table 1. Age group $>60$ years represented the highest prevalence $(32.8 \%)$. Male was having higher prevalence than female $(53.5 \%)$.

Thyroid cancer was most common (19.1\%) followed by oral cancer $(14.3 \%)$. The subsites wise frequency distribution is shown in Table 2.

Most common presentation was swelling (55.4\%) followed by non-healing ulcer $(14.3 \%)$. The distribution frequency is shown in Table 3.

Analysis of clinical parameters were done with subsites using Pearson chi-square test. Male patients and having history of tobacco/alcohol use had more site specific cancer statistically significantly (Table 4).

Table 1: Age distribution among the study
\begin{tabular}{lccc} 
participants $(\mathbf{n}=\mathbf{5 6})$ & \\
\hline $\begin{array}{l}\text { Age } \\
\text { ( in years) }\end{array}$ & Female ( $\mathbf{n}, \%)$ & Male ( $\mathbf{n}, \%)$ & Total ( $\mathbf{n}, \%)$ \\
\hline$\leq 20$ & $1(1.7 \%)$ & $0(0 \%)$ & $1(1.7 \%)$ \\
$21-40$ & $8(14.3 \%)$ & $6(10.7 \%)$ & $14(25 \%)$ \\
$41-60$ & $8(14.3)$ & $9(16.1 \%)$ & $17(30.3 \%)$ \\
$\geq 61$ & $9(16.1 \%)$ & $15(26.7 \%)$ & $24(32.8 \%)$ \\
\hline
\end{tabular}

\begin{tabular}{lc}
$\begin{array}{l}\text { Table 2: Subsites wise frequency distribution of } \\
\text { cancer }(\mathbf{n = 5 6 )}\end{array}$ \\
\hline Subsites & Number , $\mathbf{n}$ ( \%) \\
\hline Oral cavity & $8(14.3)$ \\
Oro-pharynx & $3(5.3)$ \\
Nasopharynx & $4(7.1)$ \\
Hypopharynx & $2(3.5)$ \\
Larynx & $5(8.9)$ \\
Sinonasal & $5(8.9)$ \\
Thyroid & $9(16.1)$ \\
Salivary gland & $5(8.9)$ \\
Lymphoma & $6(10.7)$ \\
CUP ( Carcinoma of unknown & $4(7.1)$ \\
primary with neck node ) & \\
Cervical Oesophagus & $3(5.3)$ \\
Pinna & $1(1.7)$ \\
\hline
\end{tabular}

\begin{tabular}{lc}
$\begin{array}{l}\text { Table 3: Clinical Presentation of the patients } \\
(\mathbf{n}=\mathbf{5 6})\end{array}$ & \multicolumn{1}{|c}{ Number of patients , $\mathbf{n}(\%)$} \\
\hline Chief complain & $31(55.4)$ \\
\hline Swelling & $8(14.3)$ \\
Ulcer & $5(8.9)$ \\
Dysphagia & $2(3.6)$ \\
Odynophagia & $4(7.1)$ \\
Voice change & $5(8.9)$ \\
Nasal obstruction & $1(1.8)$ \\
Others & \\
\hline
\end{tabular}

\section{DISCUSSION}

Since head neck cancer has increasing incidence in Asian country, Nepal is not an exception. Eastern region has different geographical variation with social acceptance of tobacco and alcohol related substance use, analysis of region specific burden is need of an hour, especially during COVID -19 pandemic because it will reflect the awareness. Early reporting to hospital leads to early diagnosis and so high chance of cure in early stage.

In our present study, median age of diagnosis was 59.5 years with advancing age had high prevalence $32.8 \%$ in age $>60$ years' group). Also, male had higher prevalence $(53.5 \%)$ with M: F was 1.15:1. Previous studies from Nepal were in concordance with ours. ${ }^{5-7}$ Study by Dixit et all found mean age 52 years with M: F ratio was $1.3: 1 .^{5}$ 


\begin{tabular}{|c|c|c|c|c|c|c|c|c|}
\hline $\begin{array}{l}\text { Clinical } \\
\text { parameters }\end{array}$ & $\begin{array}{l}\text { Oral } \\
\text { cavity }\end{array}$ & $\begin{array}{c}\text { Pharynx } \\
\text { (naso/oro/hypo) }\end{array}$ & Larynx & Sino-nasal & Thyroid & $\begin{array}{l}\text { Salivary } \\
\text { gland }\end{array}$ & Others & $\begin{array}{l}\text { Pearson Chi-square test } \\
\text { ( } p \text { value) }\end{array}$ \\
\hline \multicolumn{9}{|c|}{ Age (in years ) } \\
\hline$\leq 40$ & 1 & 0 & 0 & 3 & 3 & 3 & 5 & 0.058 \\
\hline$>40$ & 7 & 9 & 5 & 2 & 7 & 2 & 9 & \\
\hline \multicolumn{9}{|l|}{ Sex } \\
\hline Female & 2 & 3 & 2 & 2 & 9 & 0 & 8 & 0.021 \\
\hline Male & 6 & 6 & 3 & 3 & 1 & 5 & 6 & \\
\hline \multicolumn{9}{|l|}{ Addiction } \\
\hline No & 1 & 3 & 1 & 3 & 10 & 4 & 7 & 0.004 \\
\hline Yes & 7 & 6 & 4 & 2 & 0 & 1 & 7 & \\
\hline
\end{tabular}

The current study found most common site was thyroid cancer $(16.1 \%)$ followed by oral cancer $(14.3 \%)$. In female, thyroid was most common. Study by Dixit et al showed oral cancer as most common overall $(31.6 \%)$ and thyroid as most common in female $(24.03 \%) .{ }^{5}$ Some study conducted in Nepal found larynx and pharynx were most common. ${ }^{7-9}$ We also noticed $10.7 \%$ cases were lymphoma. Study from Nepal by Dixit et al, Thapa et al, Bastakota et al and Layrado et al observed its prevalence as $12.9 \%, 1 \%, 5 \%$ and $1.5 \%$ respectively. ${ }^{5-7,10}$ The discordance might be because of difference of surgical and non-surgical facilities availability institution wise and geographical variation. We also noticed prevalence of carcinoma of unknown primary with neck node (CUP) as $4 \%$. None of the previously published paper from Nepal had mentioned it. ${ }^{5-7}$ Our finding is concordance with the European Society for Medical Oncology (ESMO) guideline. ${ }^{11}$

Clinical presentation is site specific. Thyroid cancer present as neck swelling, oral cancer as non-healing ulcer with or without neck node swelling and laryngeal cancer as voice change. In our case, overall most common presentation was swelling $(55.4 \%)$ followed by ulcer $(14.3 \%)$.

Our study is the probably first study evaluating clinicodemographic profile for head neck cancer patients from eastern Nepal during the COVID-19 pandemic. It has concisely incorporated all subsites. Still we suggest multicentre large sample size with follow up data required to have proper oncological subsite wise outcome from Nepal like across the globe.

\section{CONCLUSIONS}

Most common subsite is thyroid followed by oral cavity. Swelling is most common clinical presentation followed by non-healing ulcer. Median interval of onset of symptom and hospital visit was 3.5 months. Advancing age, male sex and history of tobacco/alcohol use were risk factors.

\section{ACKNOWLEDGEMENT}

The authors thank the members of Department of Otorhinolaryngology and head neck surgery for their support.

\section{REFERENCES}

1. Bray F, Ferlay J, Soerjomataram I, Siegel RL, Torre LA and Jemal A. Global cancer statistics 2018: GLOBOCAN estimates of incidence and mortality worldwide for 36 cancers in 185 countries. CA Cancer J Clin. 2018 ;68(6):394-424.

https://doi.org/10.3322/caac.21492

2. Population based cancer registry in Nepal-2018: Nepal health research council Available at: http://nhrc.gov.np/wp-content/ uploads/2019/04/Progress-Interim__cancer.pdf

3. Pfister DG, Spencer S, Adelstein D, Adkins D, Anzai Y, Brizel DM, et al. Head and Neck Cancers, Version 2.2020, NCCN Clinical Practice Guidelines in Oncology. J Natl Compr Canc Netw. 2020 ;18(7):873-898.

https://doi.org/10.6004/jnccn.2020.0031

4. Mendenhall WM, Strojan P, Silver CE, Owen RP, Rinaldo A, Shah AR, et al. When is radiation therapy in head and neck squamous cell carcinoma not indicated?. Eur Arch Otorhinolaryngol. 2014; 271: 2849-2850.

https://doi.org/10.1007/s00405-013-2772-x

5. Dixit S, Upadhyaya C, Humagain M, Srii R and Marla V. Clinicohistopathological Survey of Head and Neck Cancer at Tertiary Health Care Centre -Dhulikhel Hospital. Kathmandu Univ Med J. 2016;54(2):167-171.

6. Baskota DK, Agrawal R, Prasad R and Sinha BK. Distribution of malignancies in head and neck regions and their management. J Nepal Med Assoc. 2005;44(159):68-72.

7. Thapa N, Jha AK, Rijal JP and Shah A. Study on head and neck tumours presented in ENT OPD of Nepal Medical College Teaching Hospital. Nepal Med Coll J. 2003;5(2):79-81.

8. Franceschi S, Bidoli E, Herrero R and Muñoz N. Comparison of cancers of the oral cavity and pharynx worldwide: etiological clues. Oral Oncol. 2000 ;36(1):106-115.

https://doi.org/10.1016/S1368-8375(99)00070-6

9. Pradhananga KK, Baral M and Shrestha BM. Multi-institution hospital-based cancer incidence data for Nepal: an initial report. Asian Pac J Cancer Prev. 2009 ;10(2):259-262.

10. Lasrado S, Prabhu P, Kakria A, Kanchan T, Pant S, Sathian B, et al. Clinicopathological profile of head and neck cancers in the Western development region, Nepal: a 4-year snapshot. Asian 
Pac J Cancer Prev. 2012;13(12):6059-6062.

https://doi.org/10.7314/APJCP.2012.13.12.6059

11. Fizazi K, Greco FA, Pavlidis N, Daugaard G, Oien K and
Pentheroudakis G. Cancers of unknown primary site: ESMO Clinical practice guidelines. Ann Oncol. 2015; 26: v133-v138.

https://doi.org/10.1093/annonc/mdv305

\section{Author's Contribution:}

RT - Concept, design of the study, preparation of manuscript draft, statistical analysis, result interpretation, review of literature; SKT - Coordination, review of literature, manuscript preparation.

\section{Work attributed to:}

Nobel Medical College Teaching Hospital, Kanchanbari, Biratnagar 56700, Nepal.

Orcid ID:

Dr. Rishikesh Thakur - (1) https://orcid.org/0000-0002-6234-5157

Dr. Sanjeev Kumar Thakur - (i) https://orcid.org/0000-0002-2855-1766

Source of Funding: None, Conflict of Interest: None. 